\title{
Cálcio e fitorreguladores no desenvolvimento e estado nutricional de Mentha spicata x suaveolens cultivada em solução nutritiva
}

\author{
PICHI, D.G. ${ }^{1}$; ALMEIDA, A.C.S. ${ }^{2}$; JAMAMI, N. ${ }^{3}$; SALVI JÚNIOR, A. ${ }^{4}$; SACRAMENTO, L.V.S. ${ }^{4 *}$ \\ ${ }^{1}$ Instituto de Química, UNESP, Núcleo de Bioensaios, Biossíntese e Ecofisiologia de Produtos Naturais - NuBBE, \\ CEP: 14800-900, Araraquara-Brasil ${ }^{2}$ Prefeitura de Araraquara, CEP: 14801-300, Araraquara-Brasil ${ }^{3}$ CATI-SAA, \\ Escritório de Desenvolvimento Rural de Araraquara, CEP: 14810-086, Araraquara-Brasil ${ }^{4}$ Faculdade de Ciências \\ Farmacêuticas, UNESP, Caixa Postal 502, CEP: 14801-902, Araraquara-SP */vss@fcfar.unesp.br
}

\begin{abstract}
RESUMO: O trabalho teve como objetivo estudar o desenvolvimento e o estado nutricional de Mentha spicata $\mathrm{x}$ suaveolens cultivada em diferentes níveis de Calcio em solução nutritiva com aplicação de fitorreguladores. O experimento constou de esquema fatorial (4x4) sendo quatro níveis de $\mathrm{Ca}^{2+}$ na solução nutritiva $\left(160,120,80\right.$ e $\left.40 \mathrm{mg} \mathrm{L}^{-1}\right)$ e três aplicações foliares, com intervalos de 15 dias, de ácido naftaleno acético (NAA), ácido giberélico $\left(\mathrm{GA}_{3}\right)$, benzinaladenina (BA) e água destilada como testemunha. As plantas foram coletadas 60 dias após a transferência para a solução e avaliadas as variáveis, matéria fresca e seca, área foliar e número de folhas; volume, comprimento e superfície radiculares e teores de $\mathrm{Ca}, \mathrm{K}, \mathrm{Mg}, \mathrm{N}$ e $\mathrm{P}$ das folhas. As variáveis foram submetidas à análise de variância e as médias comparadas pelo teste Tukey. Não foram encontradas diferenças entre os níveis de Ca para a produção de biomassa. A auxina não influenciou a matéria seca das plantas, embora tenha aumentado os teores foliares de $\mathrm{Ca}$; a citocinina acarretou diminuição da matéria seca total e a giberelina aumento da matéria seca do caule. A variação de $\mathrm{Ca}^{2+}$ não influenciou os teores foliares de N, P, Ke Mg. Houve resposta para aplicação de $\mathrm{Ca}^{2+}$, com teores foliares atingindo o máximo de $15,73 \mathrm{mg} \mathrm{kg}^{-1}$ na dose de 137,81 $\mathrm{mg} \mathrm{L}^{-1}$ pela análise de regressão.
\end{abstract}

Palavras-chave: hortelã, auxina, giberelina, citocinina, plantas medicinais

\begin{abstract}
Calcium and plant growth regulators on the development and nutritional status of Mentha spicata x suaveolens cultivated in nutrient solution. This study aimed to verify the development and the nutritional status of Mentha spicata $x$ suaveolens cultivated under different $\mathrm{Ca}^{2+}$ levels in nutrient solution with application of plant growth regulators. The experiment was in factorial design (4X4) with four $\mathrm{Ca}^{2+}$ levels in the nutrient solution $(160,120,80$ and $40 \mathrm{mg}$ $\mathrm{L}^{-1}$ ) and three leaf applications, at 15-day intervals, of naphthalene acetic acid (NAA), gibberellic acid $\left(\mathrm{GA}_{3}\right)$, benzyladenine (BA) and distilled water as control. Plants were harvested at 60 days after transferring to the nutrient solution and the following variables were evaluated fresh and dried matter, leaf area, number of leaves, volume, length and surface of roots, and leaf content of $\mathrm{Ca}, \mathrm{K}$, $\mathrm{Mg}, \mathrm{N}$ and $\mathrm{P}$. The variables were subjected to analysis of variance and means compared by Tukey's test. There were no differences between Ca levels for biomass production. The auxin did not influence the dry matter of plants although it increased the leaf content of $\mathrm{Ca}^{2+}$, the cytokinin reduced total dry matter and the gibberellin increased the stem dry matter. The change in $\mathrm{Ca}^{2+}$ did not influence the leaf content of N, P, K and Mg. There was response for the application of $\mathrm{Ca}^{2+}$, reaching the maximum of $15.73 \mathrm{mg} \mathrm{L}^{-1}$ leaf content at the level of $137.81 \mathrm{mg} \mathrm{L}^{-1}$, according to regression analysis.
\end{abstract}

Key words: mint, auxin, gibberellin, cytokinin, medicinal plants

\section{INTRODUÇÃO}

O cultivo de plantas de interesse farmacêutico vem sendo realizado em larga escala e está em expansão tanto no Brasil como em outros países. Para tanto, plantas silvestres estão sendo introduzidas a novas condições de cultivo (Vieira \& Silva, 2002).

Recebido para publicação em 30/06/2009

Aceito para publicação em 23/04/2012

Rev. Bras. PI. Med., Botucatu, v.14, n.3, p.446-452, 2012. 
Como resposta à demanda farmacêutica, a obtenção de princípios ativos vegetais está deixando de ser extrativista e assumindo caráter produtivo com sustentabilidade. Na busca por qualidade superior da matéria prima de origem vegetal, o cultivo sistemático aparece como uma saída promissora. A pesquisa agronômica deve fornecer informações seguras tanto para o cultivo de plantas medicinais tradicionais, como de novas espécies (Evans, 2009).

O solo é o fornecedor dos nutrientes necessários ao desenvolvimento das plantas e as práticas de adubação o suplementam. No entanto, muitos fatores além da disponibilidade de minerais influenciam o estado nutricional, em especial aqueles intrínsecos ao vegetal, o que determina a eficiência de absorção dos nutrientes (Malavolta et al., 1997).

Jeliazkova et al. (1997) trabalharam com três cultivares de Mentha piperita L. e verificaram que a adubação com N, P e K aumentou a produção de folhas e óleo essencial. As plantas responderam positivamente aos tratamentos, sendo verificados aumentos na altura e matéria fresca. Observaram-se também aumento no conteúdo de mentol de dois cultivares e inalteração para os demais constituintes do óleo.

O cultivo de plantas aromáticas e medicinais utilizando-se técnicas hidropônicas é realizado em pequena escala (Alexanyan et al., 1997; Maia, 1998; Teixeira et al., 2000), porém, apresenta tendência promissora e necessita de estudos que possam gerar informações seguras para os profissionais da área.

O cultivo em hidroponia é um sistema comprovadamente aplicável para as mais diversas culturas e eficiente para a produção de plantas herbáceas (Martinez \& Silva Filho, 1997). Para as espécies aromáticas, a hidroponia pode resultar em maior rendimento de óleo essencial em relação ao cultivo em solo (Maia, 1998). Para fins comerciais, o cultivo hidropônico da menta pode proporcionar maior retorno econômico somando-se a produção de óleo essencial obtida a cada colheita, pois estas podem ser feitas a cada 60 dias resultando em seis ciclos por ano.

Em condições de cultivo em solo, a cultura da menta pode ter até três ciclos anuais, uma vez que a colheita é recomendada com 110 dias de cultivo (Brilho, 1963).

O teor de óleo essencial e a concentração de mentol de Mentha arvensis L. é maior quando o cultivo é realizado em condições hidropônicas, comparado ao cultivo no campo (Paulus et al., 2007).

As plantas do gênero Mentha apresentam importância econômica também pela extração do óleo essencial, constituído principalmente de mentol, que é amplamente utilizado pela indústria farmacêutica, alimentícia e de higiene (Garlet, 2007).

Garlet et al. (2007) relataram que para Mentha spp. o aumento de concentração de $\mathrm{K}^{+}$em solução nutritiva reduziu o crescimento e o acúmulo de fitomassa, no entanto, proporcionou aumento no teor de óleo essencial.

De acordo com Candan \& Tarhan (2005), o conteúdo de carotenóides e a atividade de enzimas antioxidantes em Mentha pulegium aumentaram na ausência de $\mathrm{Ca}$ e foi maior que em condições de excesso, conferindo maior proteção na ausência deste nutriente.

Em plantas, o mecanismo de potencial homeostático mantém a concentração de $\mathrm{Ca}^{2+}$ no citoplasma em níveis adequados da ordem de $10^{-7}$ M. Pequenos aumentos na concentração de cálciolivre citossólico não ligados à calmodulina ou inositol, podem alterar a atividade e integridade de muitas enzimas (Taiz \& Zeiger, 2002).

Supanjani et al. (2005) relataram que em Crisantehemum coronarium L. o aumento de $\mathrm{Ca}^{2+}$ na solução nutritiva aumentou a altura, o diâmetro de caule e a superfície das folhas.

Stefanini et al. (2002) aplicaram 50 e $100 \mathrm{mg}$ $\mathrm{L}^{-1}$ de $\mathrm{GA}_{3}, 100$ e $200 \mathrm{mg} \mathrm{L}^{-1}$ de CCC e 1000 e 2000 $\mathrm{mg} \mathrm{L}^{-1}$ de etephon em plantas de Lipia alba, não observando variação de área foliar e matéria seca de folhas. Ao contrário, Barreiro et al. (2006) relataram maior desenvolvimento de plantas de manjericão devido ao aumento da área foliar e massa da matéria seca das plantas, quando submetidos a $100 \mathrm{mg} \mathrm{L}^{-1}$ de $\mathrm{GA}_{3}$, CCC e etephon.

Souza et al. (2007) relataram que plantas de hortelã apresentaram crescimento contínuo, com ganho de massa progressivo e tendências de aumento de fitomassa mesmo após o florescimento. Os resultados demonstraram também a possibilidade da colheita ser realizada a partir dos 29 dias após o transplante com o objetivo de produção de óleo essencial, o que significa redução no tempo de colheita e economia no processo de produção.

Giulietti (1997) propôs que sejam empregadas estratégias biotecnológicas, tanto fisiotecnológicas como genéticas, na produção de metabólitos vegetais de interesse farmacêutico. Dentre elas, citou a utilização de cultivos in vitro e a manipulação dos meios de cultura com o uso de fitorreguladores. Apresentou dados referentes à produção de alcalóides por células de raízes de Brugmansia candida, desdiferenciadas com graus distintos de morfogênese. As mesmas técnicas foram empregadas por Villareal et al. (1997) no isolamento de novo agente antimicótico a partir de células de Solanum chysotricum Schdl.

Este trabalho objetivou estudar o desenvolvimento e o estado nutricional de plantas de Mentha spicata $\mathrm{x}$ suaveolens quando cultivadas com diferentes níveis de cálcio em solução nutritiva e aplicação de fitorreguladores. Deve ser ressaltado que

Rev. Bras. PI. Med., Botucatu, v.14, n.3, p.446-452, 2012. 
na literatura pesquisada não foram encontrados trabalhos relacionando a nutrição de cálcio e a ação de fitorreguladores com a produtividade de Mentha spp., tampouco com outras espécies medicinais.

\section{MATERIAL E MÉTODO}

O experimento foi conduzido em casa de vegetação do Horto de Plantas Medicinais e Tóxicas da Faculdade de Ciências Farmacêuticas, UNESP, Campus de Araraquara, em delineamento de blocos ao acaso, constando de tratamentos com quatro níveis de cálcio na solução nutritiva, pulverizações de três fitorreguladores e água, com 3 repetições, totalizando 48 unidades experimentais. A espécie de hortelã utilizada no estudo foi identificada como Mentha spicata x suaveolens [sin: Mentha x villosa Huds. (Gobert et al., 2002)] da família Lamiaceae, sendo uma exsicata depositada no Herbário Rioclarense (HRCB 40831).

Estacas apicais de ramos aéreos com aproximadamente $12 \mathrm{~cm}$ foram coletadas de canteiros pré-formados e foram colocadas para enraizar em

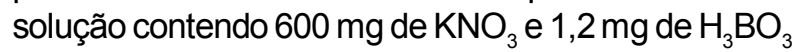
por litro, sem aeração, segundo as recomendações de Soares \& Sacramento (2001), durante 12 dias, observando-se a formação de raízes adventícias.

Após este período, duas mudas foram transferidas para vasos de PVC de 4,8 L (com face externa recoberta por tinta alumínio) contendo solução nutritiva de Hoagland \& Arnon (1950) modificada para a variação da concentração de $\mathrm{Ca}^{2+}$ caracterizando os tratamentos com 160,120, 80 e $40 \mathrm{mg} \mathrm{Ca}^{2+} \mathrm{L}^{-1}$. O pH foi monitorado diariamente e corrigido para 5,8, sempre após a reposição do volume gasto pela transpiração das plantas. As trocas de solução nutritiva foram executadas com base no valor da condutividade elétrica (CE). Procedeu-se a troca da solução dos vasos quando o valor atingia $750 \mu \mathrm{S}$ $\mathrm{cm}^{-1}$, conforme Rosolem et al. (2005). A determinação do valor CE das soluções nutritivas dos vasos foi executada a cada 5 dias de cultivo.

Após 15 dias de cultivo, foi executada a primeira das 3 aplicações foliares de fitorreguladores, com intervalo de 10 dias. As soluções de fitorreguladores aplicadas constaram de $50 \mathrm{mg} \mathrm{L}^{-1}$ de ácido naftaleno acético (NAA), $50 \mathrm{mg} \mathrm{L}^{-1}$ de ácido giberélico $\left(\mathrm{GA}_{3}\right)$ e $50 \mathrm{mg} \mathrm{L}^{-1}$ de benzinaladenina (BA). $O$ tratamento testemunha para este fator constou da aplicação de água destilada. Todas as soluções (incluindo a testemunha) receberam a adição de alquilfenol-poliglicoléter como surfatante (Extravon $\left.{ }^{\circledR}\right)$, na dose de $0,2 \mathrm{~mL} \mathrm{~L}^{-1}$.

As pulverizações destas soluções sobre as plantas foram executadas com umidade relativa do ar (UR) a $50 \pm 5 \%$ controlada pelo dispositivo de névoa da casa de vegetação.
Após 60 dias de cultivo, as plantas foram coletadas e conduzidas para a determinação da massa da matéria fresca das raízes, folhas e caules; área foliar estimada pela tomada da largura e do comprimento com base em Silva et al. (2002), considerando-se $10 \%$ da massa total da matéria fresca das folhas; número de folhas expandidas e comprimento radicular (Tennant, 1975), diâmetro e superfície radiculares (Hallmark \& Barber, 1984).

A secagem foi realizada em estufa de circulação forçada de ar a $65^{\circ} \mathrm{C}$ até obtenção de massa constante. Em seguida determinou-se a massa da matéria seca de folhas, caules e raízes e procedeu-se a determinação de $\mathrm{Ca}, \mathrm{P}, \mathrm{Mg}, \mathrm{Ke} \mathrm{N}$ nos tecidos foliares, segundo Malavolta et al. (1997).

Os resultados foram submetidos à análise de variância pelo Teste $\mathrm{F}$, com as diferenças entre médias comparadas pelo Teste de Tukey a $5 \%$ de probabilidade e análise de regressão para os teores foliares de $\mathrm{Ca}$, segundo as recomendações de Banzatto \& Kronka (1992).

\section{RESULTADOE DISCUSSÃO}

O cultivo de Mentha spicata x suaveolens em solução nutritiva proporcionou a obtenção de plantas bem desenvolvidas, muito tenras, apresentando, em média, elevados teores de água $(88 \pm 3 \%)$, comportamento semelhante ao obtido por Singh et al. (2001) em Mentha spicata, o que pode dificultar a conservação pós-colheita, bem como, depreciar a aparência do produto no comércio, em decorrência da perda de água e consequente perda da turgescência. Não foram verificadas interações entre o fator nutricional (níveis de $\mathrm{Ca}^{2+}$ na solução) e a aplicação dos fitorreguladores para as variáveis estudadas, indicando que para plantas de Mentha spicata $x$ suaveolens os efeitos dos mesmos ocorrem de maneira independente.

A análise estatística não revelou diferenças significativas para os efeitos dos níveis de $\mathrm{Ca}^{2+}$ na solução nutritiva sobre a produção de biomassa (Tabela 1). No caso da hortelã, os ramos aéreos frescos são considerados um produto de interesse econômico, por serem comercializados in natura ou após processo de secagem. Em ambos os casos, analisando-se os valores obtidos para a produção de matéria fresca e seca de folhas e caules, diferenças estatísticas não foram encontradas entre os tratamentos.

A aplicação de auxina reduziu a produção de matéria seca da folha e não proporcionou diferenças no caule e na raiz. $O$ uso de giberelina resultou em aumento da massa do caule, e diminuição da massa fresca da raiz e das massas secas de folha, caule e raiz, e a citocinina teve efeito negativo sobre a biomassa das plantas reduzindo, em alguns casos, 
TABELA1. Valores médios de biomassa em plantas de Mentha spicata $x$ suaveolens, submetidas a quatro níveis de $\mathrm{Ca}^{2+}$ na solução nutritiva.

\begin{tabular}{|c|c|c|c|c|c|c|c|c|}
\hline \multicolumn{5}{|c|}{ Matéria Fresca (g) } & \multicolumn{4}{|c|}{ Matéria Seca (g) } \\
\hline $\mathrm{Ca}^{2+}\left(\mathrm{mg} \mathrm{L}^{-1}\right)$ & Folhas & Caule & Raiz & Total & Folhas & Caule & Raiz & Total \\
\hline 160 & $55,04 a$ & $57,34 a$ & $25,79 a$ & $138,12 a$ & $7,16 a$ & $7,18 a$ & $1,65 a$ & $15,99 a$ \\
\hline 120 & $54,15 a$ & $54,13 a$ & $24,53 a$ & $132,70 a$ & $7,15 a$ & $6,67 a$ & $1,52 \mathrm{a}$ & $15,94 a$ \\
\hline 80 & $49,55 a$ & $50,69 a$ & $19,36 a$ & $119,60 a$ & $5,65 a$ & $5,63 a$ & $1,07 a$ & $12,35 a$ \\
\hline 40 & $56,22 a$ & $59,07 a$ & $23,20 a$ & $138,60 a$ & $7,48 a$ & $7,13 a$ & $1,41 \mathrm{a}$ & $16,02 a$ \\
\hline
\end{tabular}

Médias seguidas da mesma letra na coluna, não diferem entre si pelo Teste Tukey a $5 \%$.

até duas vezes esta variável (Tabela 2). Diferentemente, Scavroni et al. (2006) trabalhando com ácido giberélico e citocinina em Mentha piperita L., obtiveram aumento da massa da matéria seca das plantas, assim como, Capaldi (2007) verificou aumento de massa foliar de Mikania glomerata. Stefanini et al. (2002), trabalhando com $\mathrm{GA}_{3}$ em erva cidreira brasileira, não obtiveram aumento de massa seca do caule, das folhas e massa seca total. Stefanini \& Rodrigues (1999) relataram o aumento de massa fresca foliar com $\mathrm{GA}_{3}$ em Stevia rebaudiana.

As médias de área foliar e do número de folhas podem ser observadas na Tabela 3. A interação entre os fatores não foi significativa e os níveis de cálcio na solução de crescimento não afetaram a área foliar. A aplicação de giberelina apenas tendeu a diminuir a área foliar das plantas, enquanto houve redução desta variável pela aplicação da auxina e citocinina. A ausência de resposta com a aplicação de giberelina foi semelhante ao resultado obtido por Stefanini et al. (2002) em trabalho realizado com erva cidreira brasileira. Embora não tenham sido verificadas diferenças, as médias do número de folhas, exclusivamente do ponto de vista biológico revelaram tendência à diminuição ao serem pulverizadas com fitorreguladores, principalmente em relação à citocinina que reduziu em $22,5 \%$ o número de folhas em relação à testemunha. Sob a mesma ótica, $80 \mathrm{e}$ $120 \mathrm{mg} \mathrm{L}^{-1}$ foram os níveis de $\mathrm{Ca}^{2+}$ que favoreceram tendência à maior quantidade de folhas.

$O$ sistema radicular das plantas também foi analisado quanto às características morfológicas. A análise de variância não apontou significância para os efeitos dos fatores estudados. Os níveis mais elevados de $\mathrm{Ca}^{2+}$ em solução tenderam a propiciar raízes menos volumosas e mais finas (Tabela 4 ). No

TABELA2. Valores médios de biomassa de plantas de Mentha spicata x suaveolens, submetidas a aplicações de fitorreguladores $\left(50 \mathrm{mg} \mathrm{L}^{-1}\right)$.

\begin{tabular}{lcccccccccc}
\hline \multicolumn{4}{c}{ Matéria Fresca $(\mathrm{g})$} & \multicolumn{4}{c}{ Matéria Seca $(\mathrm{g})$} \\
\hline Tratamentos & Folhas & Caule & Raiz & Total & & Folhas & Caule & Raiz & Total \\
\hline Água & $67,55 \mathrm{a}$ & $56,21 \mathrm{~b}$ & $26,89 \mathrm{a}$ & $150,66 \mathrm{a}$ & & $9,23 \mathrm{a}$ & $7,54 \mathrm{ab}$ & $1,85 \mathrm{a}$ & $18,62 \mathrm{a}$ \\
Auxina & $54,05 \mathrm{ab}$ & $47,84 \mathrm{bc}$ & $34,92 \mathrm{a}$ & $136,81 \mathrm{a}$ & & $6,57 \mathrm{~b}$ & $5,88 \mathrm{bc}$ & $1,97 \mathrm{a}$ & $14,43 \mathrm{ab}$ \\
Giberelina & $50,57 \mathrm{ab}$ & $84,49 \mathrm{a}$ & $16,39 \mathrm{~b}$ & $151,42 \mathrm{a}$ & & $6,05 \mathrm{~b}$ & $9,32 \mathrm{a}$ & $1,03 \mathrm{~b}$ & $17,00 \mathrm{a}$ \\
Citocinina & $42,78 \mathrm{~b}$ & $32,69 \mathrm{c}$ & $14,67 \mathrm{~b}$ & $90,09 \mathrm{~b}$ & & $5,59 \mathrm{~b}$ & $3,88 \mathrm{c}$ & $0,79 \mathrm{~b}$ & $10,26 \mathrm{~b}$ \\
\hline
\end{tabular}

Médias seguidas da mesma letra na coluna, não diferem entre si pelo Teste Tukey a $5 \%$.

TABELA3. Área foliar e número de folhas estimados para plantas de Mentha spicata x suaveolens, submetidas a diferentes níveis de $\mathrm{Ca}^{2+}$ e aplicações de fitorreguladores $\left(50 \mathrm{mg} \mathrm{L}^{-1}\right)$ no cultivo em solução nutritiva.

\begin{tabular}{|c|c|c|c|c|c|c|c|}
\hline \multicolumn{4}{|c|}{ Tratamentos } & \multicolumn{4}{|c|}{ Níveis de $\mathrm{Ca}^{2+}\left(\mathrm{mg} \mathrm{L}^{-1}\right)$} \\
\hline Água & Auxina & Giberelina & Citocinina & 160 & 120 & 80 & 40 \\
\hline & & & Área foliar* & & & & \\
\hline $2759 A$ & 1928B & $2256 A B$ & 1481B & $2090 A$ & $2197 A$ & $1908 A$ & $2229 \mathrm{~A}$ \\
\hline $913 \mathrm{~A}$ & $736 \mathrm{~A}$ & 795A & $708 \mathrm{~A}$ & $744 \mathrm{~A}$ & 793A & $878 A$ & 737A \\
\hline
\end{tabular}

${ }^{*}$ Referente a 2 plantas (vaso); médias seguidas pela mesma letra maiúscula na linha não diferem entre si pelo Teste Tukey a $5 \%$ de probabilidade. 
TABELA 4. Valores médios de comprimento, diâmetro, superfície e volume radiculares de plantas de Mentha spicata $\mathrm{x}$ suaveolens submetidas a crescimento em solução nutritiva com variação dos níveis de $\mathrm{Ca}^{2+}$.

\begin{tabular}{ccccc}
\hline $\begin{array}{c}\text { Níveis de Ca } \\
\left(\mathbf{m g ~ L}^{-1}\right)\end{array}$ & $\begin{array}{c}\text { Comprimento } \\
\text { radicular }(\mathbf{m})\end{array}$ & $\begin{array}{c}\text { Diâmetro } \\
\text { médio }(\mathbf{m m})\end{array}$ & $\begin{array}{c}\text { Superfície } \\
\text { radicular }\left(\mathbf{c m}^{2}\right)\end{array}$ & $\begin{array}{c}\text { Volume } \\
\text { radicular(mL) }\end{array}$ \\
\hline 160 & $33501 \mathrm{a}$ & $0,029 \mathrm{a}$ & $3074,3 \mathrm{a}$ & $23,19 \mathrm{a}$ \\
120 & $29922 \mathrm{a}$ & $0,028 \mathrm{a}$ & $2636,2 \mathrm{a}$ & $19,35 \mathrm{a}$ \\
80 & $27973 \mathrm{a}$ & $0,032 \mathrm{a}$ & $2823,7 \mathrm{a}$ & $24,47 \mathrm{a}$ \\
40 & $31797 \mathrm{a}$ & $0,031 \mathrm{a}$ & $3137,1 \mathrm{a}$ & $25,79 \mathrm{a}$ \\
\hline
\end{tabular}

*Média de 2 plantas (vaso); Médias seguidas da mesma letra na coluna, não diferem entre si pelo Teste Tukey a $5 \%$ de probabilidade.

entanto, esta tendência não correspondeu à hipótese de que a superfície e o comprimento da raiz aumentariam com a maior concentração de $\mathrm{Ca}^{2+}$ disponível em solulção.

O estado nutricional da planta foi avaliado quanto aos valores de N, P, K, Ca e Mg. Excetuandose o cálcio, a análise de regressão não foi significativa para estes teores considerando os tratamentos com cálcio na solução nutritiva. A Tabela 5 apresenta os resultados para as concentrações dos elementos analisados nos tecidos foliares. Como a solução nutritiva empregada somente foi diferenciada quanto à concentração de $\mathrm{Ca}^{2+}$, pode-se dizer que este aspecto não favoreceu, tampouco facilitou, a absorção de N, P, Ke, sobretudo de Mg. Choudbury et al. (2006) relataram valores médios de cálcio $\left(12,4 \pm 3,5 \mathrm{mg} \mathrm{g}^{-1}\right)$ em folhas de Mentha spicata, magnitude próxima à encontrada neste experimento; o mesmo raciocínio pode ser aplicado para o fósforo $\left(3,88 \pm 0,94 \mathrm{mg} \mathrm{g}^{-1}\right)$ e magnésio $\left(4,83 \pm 0,92 \mathrm{mg} \mathrm{g}^{-1}\right)$, excetuando-se o potássio $\left(23,4 \pm 12,1 \mathrm{mg} \mathrm{g}^{-1}\right)$ que mostrou no presente estudo maiores valores. Blank et al. (2006) relataram para Mentha piperita valores maiores que os verificados neste estudo para o $\mathrm{Ca}$ $\left(16,12 \mathrm{~g} \mathrm{~kg}^{-1}\right)$ e $\mathrm{Mg}\left(9,34 \mathrm{~g} \mathrm{~kg}^{-1}\right)$; valor semelhante foi encontrado para $\mathrm{N}\left(46,20 \mathrm{~g} \mathrm{~kg}^{-1}\right) \mathrm{e}$, valores inferiores para $\mathrm{P}\left(3,05 \mathrm{~g} \mathrm{~kg}^{-1}\right)$ e K $\left(24,56 \mathrm{~g} \mathrm{~kg}^{-1}\right)$. Rodrigues et al. (2004) relataram também em Mentha piperita teores foliares dos nutrientes associados ao teor máximo de óleo aos 95 dias de cultivo $\left(\mathrm{em} \mathrm{g} \mathrm{kg}^{-1}\right)$ : $\mathrm{N}=37,2 ; \mathrm{K}=21,2$, valores inferiores aos obtidos neste trabalho; $\mathrm{Ca}=9,3$, valor inferior em concentrações mais elevadas de Ca na solução nutritiva; $\mathrm{Mg}=3,8$ e P=3,9 com valores próximos ao deste estudo.

Para o fator cálcio, a análise de regressão foi significativa para $p \leq 0,01$, evidenciando a resposta das plantas aos diferentes níveis na solução de cultivo. De acordo com a curva de regressão, os teores de Ca nas folhas de Mentha spicata $x$ suaveolens atingiram um máximo de $15,73 \mathrm{mg} \mathrm{kg}^{-1}$ na dose de $137,81 \mathrm{mg} \mathrm{L}^{-1}$ (Figura 1). Supanjani et al. (2005) também relataram aumento do teor foliar ${\mathrm{de} \mathrm{Ca}^{2+} \mathrm{com}}^{2}$ aumento dos níveis de concentração na solução em Crisantehemum coronarium $\mathrm{L}$.

A média geral dos tratamentos para os teores de cálcio atingiu o valor de $13,35 \mathrm{~g} \mathrm{~kg}^{-1}$, ficando $10,4 \%$ inferior àquela obtida por Maia (1998), que relatou 14,9 $\mathrm{g} \mathrm{Ca} \mathrm{kg}^{-1}$ para o cultivo de Mentha arvensis em solução nutritiva completa empregando um máximo de 200 mg Ca L-1. Garlet (2007) cultivando a mesma espécie

TABELA 5. Concentrações de $\mathrm{Ca}, \mathrm{N}, \mathrm{P}, \mathrm{K}$ e Mg em tecidos foliares de plantas de Mentha spicata x suaveolens, submetidas a diferentes níveis de $\mathrm{Ca}^{2+}$ e aplicações de fitorreguladores $\left(50 \mathrm{mg} \mathrm{L}^{-1}\right)$ no cultivo em solução nutritiva.

\begin{tabular}{crrrrr}
\hline Níveis de Ca mg L-1 & $\mathrm{Ca}$ & $\mathrm{N}$ & $\mathrm{P}$ & $\mathrm{K}$ & $\mathrm{Mg}$ \\
\cline { 2 - 6 } & $9,2 \mathrm{a}$ & $48,3 \mathrm{a}$ & $3,3 \mathrm{a}$ & $61,9 \mathrm{a}$ & $3,4 \mathrm{a}$ \\
& $14,3 \mathrm{a}$ & $47,4 \mathrm{a}$ & $3,6 \mathrm{a}$ & $63,1 \mathrm{a}$ & $3,8 \mathrm{a}$ \\
80 & $14,5 \mathrm{a}$ & $45,5 \mathrm{a}$ & $3,7 \mathrm{a}$ & $49,9 \mathrm{a}$ & $4,2 \mathrm{a}$ \\
120 & $15,4 \mathrm{a}$ & $46,9 \mathrm{a}$ & $3,7 \mathrm{a}$ & $69,2 \mathrm{a}$ & $3,4 \mathrm{a}$ \\
160 & & & & & \\
\hline Tratamentos & $12,0 \mathrm{~b}$ & $49,2 \mathrm{a}$ & $3,2 \mathrm{a}$ & $54,7 \mathrm{a}$ & $3,8 \mathrm{a}$ \\
água & $17,6 \mathrm{a}$ & $48,4 \mathrm{a}$ & $3,7 \mathrm{a}$ & $52,5 \mathrm{a}$ & $3,7 \mathrm{a}$ \\
auxina & $12,8 \mathrm{~b}$ & $47,9 \mathrm{a}$ & $3,9 \mathrm{a}$ & $61,0 \mathrm{a}$ & $3,9 \mathrm{a}$ \\
giberelina & $10,9 \mathrm{~b}$ & $46,4 \mathrm{a}$ & $3,7 \mathrm{a}$ & $68,2 \mathrm{a}$ & $3,5 \mathrm{a}$ \\
citocinina &
\end{tabular}

Médias seguidas pela mesma letra minúscula na coluna, não diferem entre si pelo Teste Tukey a $5 \%$ de probabilidade. 


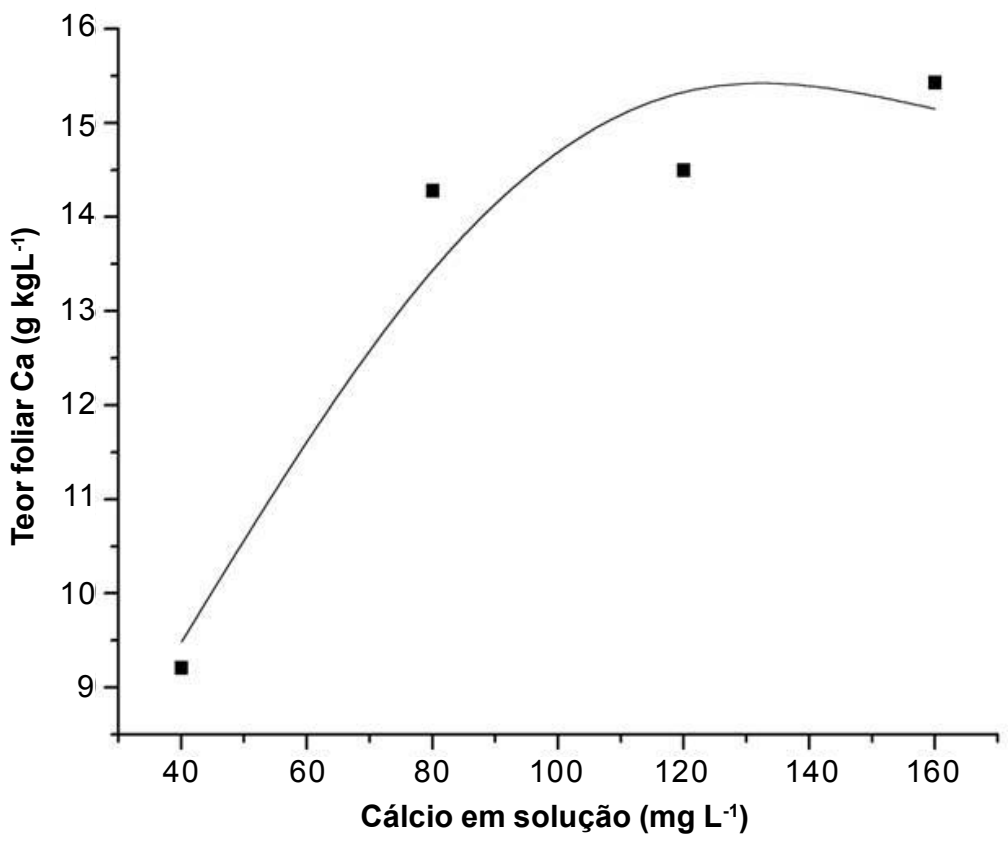

FIGURA 1. Concentração de $\mathrm{Ca}^{2+}$ nas folhas de Mentha spicata x suaveolens em função dos níveis na solução nutritiva.

em hidroponia observou teor igual a $20,45 \mathrm{~g} \mathrm{Ca} \mathrm{kg}^{-1}$ nas folhas.

O mesmo autor relatou valor ligeiramente inferior para o nitrogênio $\left(43,43 \mathrm{~g} \mathrm{~kg}^{-1}\right)$, superior para o fósforo $\left(5,22 \mathrm{~g} \mathrm{~kg}^{-1}\right)$ e magnésio $\left(10,35 \mathrm{~g} \mathrm{~kg}^{-1}\right) \mathrm{e}$, inferior para o potássio $\left(11,87 \mathrm{~g} \mathrm{~kg}^{-1}\right)$, em relação aos resultados do presente estudo.

No caso do potássio a literatura fornece informações que indicam comparativamente que $M$. spicata $\mathrm{x}$ suaveolens pode acumular mais potássio nos tecidos foliares, e, considerando que os teores dos demais macronutrientes estavam em níveis satisfatórios, sugere-se que não necessariamente houve desequilíbrios nas proporções entre estes últimos.

Quanto à aplicação de fitorreguladores, foram verificadas diferenças significativas apenas para cálcio nos tecidos foliares, sendo que os tratamentos de giberelina e citocinina não diferiram da testemunha (água). Deve ser destacada a contribuição da aplicação de auxina (NAA) para aumento do cálcio nos tecidos foliares de hortelã.

As plantas não apresentaram restrições no desenvolvimento (produção de matéria seca total, morfologia do sistema radicular e parâmetros fitométricos da parte aérea) para os níveis de cálcio estudados. A ação de fitorreguladores foi discreta, não sendo relacionada aos teores de cálcio na planta, e apresentou tendências de redução da área foliar e do número de folhas, não sendo recomendadas aplicações de auxina, giberelina e citocinina para Mentha spicata $\mathrm{x}$ suaveolens quando cultivada em hidroponia. Os tratamentos com cálcio não proporcionaram diferenças significativas nos teores foliares do nutriente, inferindo uma saturação do sistema de absorção ou de translocação, refletindo na eficiência de utilização de cálcio em Mentha.

\section{AGRADECIMENTO}

Ao Programa de Apoio ao Desenvolvimento Científico (PADC) da Faculdade de Ciências Farmacêuticas da UNESP, pelo apoio financeiro.

\section{REFERÊNCIA}

ALEXANYAN, J.S. et al. Optimization of valuable medicinal plant Motherwort (Leonurus quinquelobatus Gilib.) nutrient solution in hydroponic conditions. In: CONGRESO MUNDIAL DE PLANTAS AROMÁTICAS Y MEDICINALES PARA EL BIENESTAR DE LA HUMANIDAD, 2., 1997, Mendoza. Resumenes... Mendoza: ICMAP, ISHS, SAIPA, 1997. p.108.

BANZATTO, D.A.; KRONKA, S.N. Experimentação agrícola. Jaboticabal: Funep - FCAV/UNESP. 1992. 247p. BARREIRO, A.P. et al. Análise de crescimento de plantas de manjericão tratadas com reguladores vegetais. Bragantia, v.65, n.4, p.563-7, 2006.

BLANK, A.F. et al. Efeitos da adubação química e da calagem na nutrição de melissa e hortelã pimenta. Horticultura Brasileira, v.24, n.2, p.195-8, 2006.

BRILHO, R.C. A cultura da hortelã pimenta. Manual Técnico do Engenheiro Agrônomo. Campinas: Instituto Agronômico de Campinas, 1963. 13p.

CANDAN, N.; TARHAN, L. Effects of calcium, stress on 
contents of chlorophyll and carotenoid, LPO levels, and antioxidant enzyme activities in Mentha. Journal of Plant Nutrition, v.28, n.1, p.127-39, 2005.

CAPALDI, M.L.P.M. Reguladores vegetais no desenvolvimento de plantas de guaco (Mikania glomerata Sprengel). 2007. 75p. Dissertação (Mestrado Área de Concentração em Fitotecnia) - Universidade de Marília, Marília.

CHOUDBURY, R.P.; KUMAR, A.; GARG, A.N. Analysis of Indian mint (Mentha spicata) for essencial, trace and toxic elements and its antioxidant behavior. Journal of Pharmaceutical and Biomedical Analysis, v.41, n.3, p.825-32, 2006.

EVANS, W.C. Trease and Evans Pharmacognosy. 16.ed. New York: Elsevier, 2009. p.81-132.

GARLET, T.A.B. Produtividade, teor e composição do óleo essencial de espécies de Mentha L. (Lamiaceae) cultivadas em hidroponia com variação de potássio. 2007. 112p. Tese (Doutorado - Área de Concentração em Produção Vegetal) - Universidade Federal de Santa Maria, Santa Maria.

GARLET, T.A.B. et al. Crescimento e teor de óleo essencial de mentas com diferentes concentrações de potássio na solução nutritiva. Horticultura Brasileira, v.25 n.2, p.230-7, 2007.

GIULIETTI, A.M. Estrategias biotecnologicas para la producción de metabolitos vegetales de interés farmacéutico. In: CONGRESO MUNDIAL DE PLANTAS AROMÁTICAS Y MEDICINALES PARAEL BIENESTAR DE LA HUMANIDAD, 2., 1997, Mendoza. Resumenes... Mendoza: ICMAP, ISHS, SAIPA, 1997. p.L-12.

GOBERT, V. et al. Hybridization in the section Mentha (Lamiaceae) inferred from AFLP markers. American Journal of Botany, v.89, n.12, p.2017-23, 2002.

HALLMARK, W.B.; BARBER, S.A. Root growth and morphology, nutrient uptake and nutrient status of early growth of soybeans as affected by soil $\mathrm{P}$ and $\mathrm{K}$. Agronomy Journal, v.76, p.209-12, 1984.

HOAGLAND, D.R.; ARNON, D.I. The water culture method for growing plants without soil. Berkeley: California Agriculture Experimental Station Circular, n.347, 1950. 32p. JELIAZKOVA, E.A et al. NPK fertilizer and yields of peppermint, Mentha x piperita. In: CONGRESSO MUNDIAL DE PLANTAS AROMÁTICAS Y MEDICINALES PARA EL BIENESTAR DE LA HUMANIDAD, 2., 1997, Mendoza. Resumenes... Mendoza: ICMAP, ISHS, SAIPA, 1997. p.9. MAIA, N.B. Efeito da nutrição mineral na qualidade do óleo essencial da menta (Mentha arvensis L.) cultivada em solução nutritiva. In: MING, L.C. et al. (Eds.). Plantas medicinais aromáticas e condimentares: avanços na pesquisa agronômica. Botucatu: FCA/UNESP, 1998. p.81-95.

MALAVOLTA, E.; VITTI, G.C.; OLIVEIRA, S.A. Avaliação do estado nutricional das plantas: princípios e aplicações. 2.ed. Piracicaba: POTAFÓS, 1997. 319p.

MARTINEZ, H.E.P.; SILVA FILHO, J.B. Introdução ao cultivo hidropônico de plantas. Viçosa: UFV, 1997.52p. PAULUS, D. et al. Teor e qualidade do óleo essencial de menta (Mentha arvensis L.) produzida sob cultivo hidropônico e em solo. Revista Brasileira de Plantas Medicinais, v.9, n.2, p.80-7, 2007.

RODRIGUES, C.R. et al. Nutrição mineral, crescimento e teor de óleo essencial da menta em solução nutritiva sob diferentes concentrações de fósforo e épocas de coleta. Horticultura Brasileira, v.22, n.3, p.573-8, 2004. ROSOLEM, C.A.; SACRAMENTO, L.V.S.; OLIVEIRA, D.M.T. Kinetics of zinc uptake and anatomy of roots and leaves of coffee trees as affected by zinc nutrition. Journal of Plant Nutrition, v.28, p.2101-12, 2005.

SCAVRONI, J. et al. Rendimento e composição química de óleo essencial de Mentha piperita L. submetidas a aplicações giberelina e citocinina. Revista Brasileira de Plantas Medicinais, v.8, n.4, p.40-3, 2006.

SILVA, L.C. et al. Um método simples para se estimar área foliar de plantas de gergelim (Sesamum indicum L.). Revista Brasileira de Oleaginosas e Fibrosas, v.6, n.1, p.491-6, 2002.

SINGH, G.; KAWATRA, A.; SEHGAL, S. Nutritional composition of selected green leafy vegetables, herbs and carrots. Plant Foods for Human Nutrition, v.56, n.4, p.359-64, 2001.

SOARES, A.; SACRAMENTO, L.V.S. Desempenho de Mentha ssp quanto à formação de raízes adventícias em função do substrato. In: JORNADA PAULISTA DE PLANTAS MEDICINAIS, 5., 2001, Botucatu. Anais... Botucatu: FCA, IB, FM/UNESP, 2001. 107p.

SOUZA, A.A. et al. Produção de biomassa e óleo essencial de hortelã em hidroponia em função de nitrogênio e fósforo. Horticultura Brasileira, v.25, n.1, p.41-8, 2007.

STEFANINI, M.B.; RODRIGUES, S.D. Influência do ácido giberélico na produção de biomassa em Stevia rebaudiana (Bert.) Bertoni. Revista Brasileira de Plantas Medicinais, v.1, n.2, p.35-43, 1999.

STEFANINI, M.B.; RODRIGUES, S.D.; MING, L.C. Ação de fitorreguladores no crescimento da erva-cidreirabrasileira. Horticultura Brasileira, v.20, n.1, p.18-23, 2002. SUPANJANI, A.R.M. et al. Calcium effects on yield, mineral uptake and terpene components of hydroponic Crisantehemum coronarium L. Journal of Agriculture and Biological Sciences, v.1, n.2, p.146-51, 2005.

TAIZ, L.; ZEIGER, E. Plant physiology. 3.ed. Sunderland: Sinauer Associates, Inc., Publishers. 2002. 690p.

TEIXEIRA, J.P.F. et al. Óleo essencial de duas variedades de manjericão em cultivo hidropônico. In: CONGRESSO BRASILEIRO DE OLERICULTURA, 40., CONGRESSO IBERO-AMERICANO SOBRE UTILIZAÇÃO DE PLÁSTICO NAAGRICULTURA, 2., SIMPÓSIO LATINO-AMERICANO DE PRODUÇÃO DE PLANTAS MEDICINAIS, AROMÁTICAS E CONDIMENTARES, 1., 2000, São Pedro. Trabalhos apresentados e palestras... Brasília: SOB/ FCAV-UNESP, 2000. p.982-3.

TENNANT, D.A. A test of a modified line intersect method of estimating root lenght, Journal Ecology, v.63, p.9951001, 1975.

VIEIRA, R.F.; SILVA, S.R. Estratégias para conservação e manejo de recursos genéticos de plantas medicinais e aromáticas. Resultados da 1a Reunião Técnica... Brasília: Embrapa, IBAMA, MMA, CNPq, 2002. 184p.

VILLAREAL, M.L. et al. Production of a new antimycotic agent by plant cell culture. In: CONGRESO MUNDIAL DE PLANTAS AROMÁTICAS Y MEDICINALES PARA EL BIENESTAR DE LA HUMANIDAD, 2., 1997, Mendoza. Resumenes... Mendoza: ICMAP, ISHS, SAIPA, 1997. L-13p. 